\title{
Longitudinal Assessment of Strength, Functional Capacity, Oropharyngeal Function, and Quality of Life in Oculopharyngeal Muscular Dystrophy
}

Rosemarie H.M.J.M. Kroon, MA, Johanna G. Kalf, PhD, Bert J.M. de Swart, PhD, Barbara M. van der Sluijs, MD, PhD, Jeffrey C. Glennon, PhD, Vered Raz, PhD, Baziel G. van Engelen, MD, PhD,* and Corinne G.C. Horlings, MD, PhD*

Neurology ${ }^{\circledR}$ 2021;97:e1475-e1483. doi:10.1212/WNL.0000000000012640

\section{Abstract}

\section{Background and Objectives}

Oculopharyngeal muscular dystrophy (OPMD) is a late-onset, progressive muscle disease. Disease progression is known to be slow, but details on the natural history remain unknown. We aimed to examine the natural history of OPMD in a large nationwide cohort to determine clinical outcome measures that capture disease progression and can be used in future clinical trials.

\section{Methods}

Patients invited by their treating physicians or identified from the national neuromuscular database and invited family members were examined twice 20 months apart with fixed dynamometry; Medical Research Council (MRC) grading; maximum bite force and isometric tongue strength; Motor Function Measure (MFM); 10-step stair test; maximum swallowing, chewing, and speech tasks; and quality of life assessments.

\section{Results}

Disease progression was captured by 8 of 18 measures over 20 months in 43 patients with genetically confirmed OPMD. The largest deterioration was seen in deltoid muscle strength $(-27 \%$ [range $-17 \%$ to $-37 \%])$, followed by the quadriceps ( $-14 \%$ [range -6 to $-23 \%])$, iliopsoas $(-12.2 \%)$, tongue $(-9.9 \%)$, and MRC sum score $(-2.5 \%)$. The 10-step stair test $(-12.5 \%)$, MFM part D1 $(-7.1 \%)$, and maximum repetition rate of $/ \mathrm{pa} /(-5.3 \%)$ showed a significant decrease as well (all $p<0.05$ ). The Physical Functioning domain of the Short Form36 Health Survey significantly deteriorated $(p=0.044)$. No relationship was found between disease progression and genotype or disease duration $(p>0.05)$.

\section{Discussion}

Despite the slow disease progression of OPMD, this study showed that several outcome measures detected progression within 20 months. Deltoid muscle strength, measured by fixed dynamometry, showed the greatest decline. These longitudinal data provide clinical outcome measures that can be used as biomarkers in future clinical trials.

\author{
Correspondence \\ Rosemarie Kroon \\ rosemarie.kroon@ \\ radboudumc.nl
}

\section{MORE ONLINE}

CME Course

NPub.org/cmelist

\footnotetext{
*These authors contributed equally to this work.

From the Departments of Rehabilitation (R.H.M.J.M.K., J.G.K., B.J.M.d.S.) and Neurology (B.G.v.E., C.G.C.H.), Donders Institute for Brain, Cognition and Behaviour, Radboud University Medical Center, Nijmegen; Department of Neurology (B.M.v.d.S.), Gelre Hospital Zutphen, the Netherlands; Conway Institute of Biomolecular and Biomedical Research (J.C.G.), School of Medicine, University College Dublin, Ireland; Department of Human Genetics (V.R.), Leiden University Medical Centre; and Department of Neurology (C.G.C.H., Maastricht University Medical Center, Maastricht, the Netherlands.

Go to Neurology.org/N for full disclosures. Funding information and disclosures deemed relevant by the authors, if any, are provided at the end of the article. 


\section{Glossary}

CI = confidence interval; CRAMP $=$ Computer Registry of All Myopathies and Polyneuropathies; INQoL $=$ International Quality of Life; MFM = Motor Function Measure; MRC = Medical Research Council; NRRS = Normalized Residue Ratio Scale; OPMD = oculopharyngeal muscular dystrophy; SF-36 = Short Form-36; TOMASS $=$ Test of Masticating and Swallowing Solids.

Oculopharyngeal muscular dystrophy (OPMD) is an autosomal dominant, late-onset muscle disease. The estimated prevalence is $\approx 1: 100,000$, but several studies suggest that OPMD is underdiagnosed, ${ }^{1-5}$ mostly due to unfamiliarity among clinicians. ${ }^{3}$ The clinical characteristics of OPMD are ptosis due to weakness of the levator palpebrae muscle and dysphagia due to weakness of the pharyngeal muscles, ${ }^{6}$ both starting early in the disease course. ${ }^{7}$ Weakness of shoulder girdle and limb girdle muscles, even as an early sign, ${ }^{8-10}$ completes the clinical picture, but these symptoms are not always recognized as being part of OPMD, especially in the elderly.

No pharmacologic treatment is available for OPMD, but with recent developments in gene therapy, therapeutic trials in humans are forthcoming. ${ }^{11-14}$ Therefore, detailed information on the natural history and sensitive outcome measures to detect disease progression or therapy effect are urgently needed. ${ }^{15}$ Detailed analysis of the natural history will help us understand the variability in disease severity within families, which can possibly support therapy development. One small study including 8 patients with OPMD investigated disease progression over a period varying from 8 to 16 months with MRI of the muscles and the Motor Function Measure (MFM) and showed disease progression on the MRI but no disease progression on the MFM. ${ }^{16}$ No other longitudinal clinical studies of OPMD are available.

This study aims to examine in detail the natural history in a large nationwide cohort of patients with OPMD to determine clinical outcome measures that capture disease progression and can be used in future clinical trials.

\section{Methods}

\section{Patients}

Patients were invited by their treating physicians or identified from the national neuromuscular database (Computer Registry of All Myopathies and Polyneuropathies [CRAMP] $)^{17}$ in the Netherlands. Approximately 80 patients are known to be diagnosed with OPMD by a neurologist (source: CRAMP database). In addition, family members of the patients were asked to participate through an information letter. Thus, possible asymptomatic carriers and patients with subtle signs of OPMD could be included.

At baseline and at follow-up, all patients were interviewed to identify complaints related to oropharyngeal tasks (swallowing, chewing, and speaking) or to functioning of the limbs.

\section{Standard Protocol Approvals, Registrations, and Patient Consents}

The study was approved by the local medical ethics committee (study NL54606.091.15), and all patients gave signed written informed consent.

\section{Clinical Examination}

All patients were clinically examined at baseline and after \pm 20 months by the same investigator (R.H.M.J.M.K.). The measurements are explained below.

\section{Measurements of Muscle Strength}

- Fixed dynamometry (Newtons) was performed with the strength transducer KAP-S $2 \mathrm{kN}$ (Angewandte System Technik GmbH, Dresden, Germany) to measure the maximal isometric contraction of the shoulder abduction (deltoid muscle), hip flexion (iliopsoas muscle), and knee extension (quadriceps muscle). The best performance (maximum force) of the 3 measurements was used for analysis.

- Manual muscle testing was performed with the Medical Research Council (MRC) scale ranging from 0 (no muscle contraction) to 5 (maximal muscle strength) ${ }^{18}$ for neck extension and flexion, elbow extension and flexion, knee extension and flexion, hip abduction, hip flexion, foot dorsal flexion and foot plantar flexion, handgrip, wrist extension and flexion, and shoulder abduction bilaterally (score 0-130).

- Maximum bite force was measured with the Bite Force Gauge (Vrije Universiteit, Amsterdam, the Netherlands). The best performance of 3 trials was used for analysis.

- Maximum isometric tongue strength was assessed with the Iowa Oral Performance Instrument (model 2.3, IOPI Medical LLC, Woodinville, WA). Patients were instructed to push the bulb with the anterior part of the tongue against the roof of the mouth as hard as possible. The best performance of 3 trials was used for analysis. ${ }^{19}$

\section{Measurements of Functional Capacity}

- The MFM consists of 3 parts: D1, concerning stance and transfer tasks; D2, concerning tasks of axial and proximal muscles; and D3, concerning tasks using distal muscles. The outcome ranges from $0 \%$ to $100 \%$. A score of $100 \%$ implies no functional motor deficits. ${ }^{20}$

- A timed stair-walking test (10-steps) was measured in seconds. ${ }^{21}$ Patients were instructed to take the stairs as they normally would. The stairs had 1 handrail. The patients decided to hold the handrail or not.

- The Test of Masticating and Swallowing Solids (TOMASS) was performed by eating a cracker as fast as possible, measured in seconds. ${ }^{22}$ 
- The maximum swallowing capacity was measured by the maximum swallowing speed and maximum swallowing volume. For the maximum swallowing speed, patients were instructed to drink $150 \mathrm{~mL}$ water as quickly as possible. $^{23,24}$ For the maximum swallowing volume, patients were instructed to swallow a maximal amount (milliliters) of water in 1 swallow. ${ }^{25}$

- The maximum speech capacity was measured by the maximum phonation time and maximum repetition rate. ${ }^{26,27}$ Maximum phonation time measures how long a patient can produce an /a/ in seconds. Norm values are available for several languages, also in Dutch. ${ }^{28-30}$ Maximum repetition rate is the number of syllables per second during the 5 first seconds (syllables per second) of producing the monosyllabic sequences $/ \mathrm{pa} /, / \mathrm{ta} /, / \mathrm{ka} /$ and a trisyllabic sequence /pataka/. The best score of 3 trials was used in the analysis.

- Videofluoroscopy of swallowing was performed with the Digital Swallowing Workstation (model 7120, Swallowing Signals Lab, KayPENTAX, Lincoln Park, NJ) to quantify the swallowing efficiency and safety using the Normalized Residue Ratio Scale (NRRS) and the Penetration Aspiration Scale. A detailed description of these measurements is given by Kroon et al. ${ }^{31}$

- Videotapes were made of eye movements and ptosis for offline analysis by one of the authors, an experienced neurologist (C.G.C.H). Ptosis was scored on both sides on a scale from 0 to $3(0=$ no ptosis, $1=$ mild ptosis [above half of the pupil], $2=$ severe ptosis [below half of the pupil], $3=$ status after operative ptosis correction). Eye movements were scored as ophthalmoplegia present or absent.

\section{Quality of Life Scales}

For an assessment of patients' quality of life, we used the International Quality of Life (INQoL) questionnaire and the Short Form-36 (SF-36) Health Survey. ${ }^{32,33}$

\section{Statistical Analysis}

IBM SPSS Statistics (version 25; Armonk, NY) was used to conduct all statistical analyses, and values of $p<0.05$ were considered statistically significant. The interviews and structured questionnaires were analyzed by counting the number of patients who reported any (worsening of) subjective complaint in any of the domains. Individual scores on the INQoL and SF-36 health assessment were calculated according to their requirements, and mean scores were estimated per domain. The results of all clinical measures at baseline and follow-up were compared by the use of pairedsample $t$ tests to calculate the mean differences with their 95\% confidence intervals (CIs). Differences of measures that were not normally distributed at baseline were also tested with the Wilcoxon signed-rank test. The mean differences and CIs were converted into percentages of worsening. The correlation between patient characteristics (disease duration and GCN-repeat size) and disease progression on all tasks was analyzed by calculating the Spearman $\rho$ correlation coefficients.

\section{Data Availability}

The anonymized data that support the findings of this study are available from the corresponding author on reasonable request.

\section{Results}

\section{Patients}

Forty-four patients with OPMD were invited by their treating physicians or identified from the national neuromuscular database. Nineteen family members of these patients, who were therefore patients with putative OPMD, were asked to participate as well. Figure 1 shows the flowchart of participant recruitment and inclusion. After genetic testing, it appeared

Figure 1 Flowchart of Participant Recruitment and Inclusion

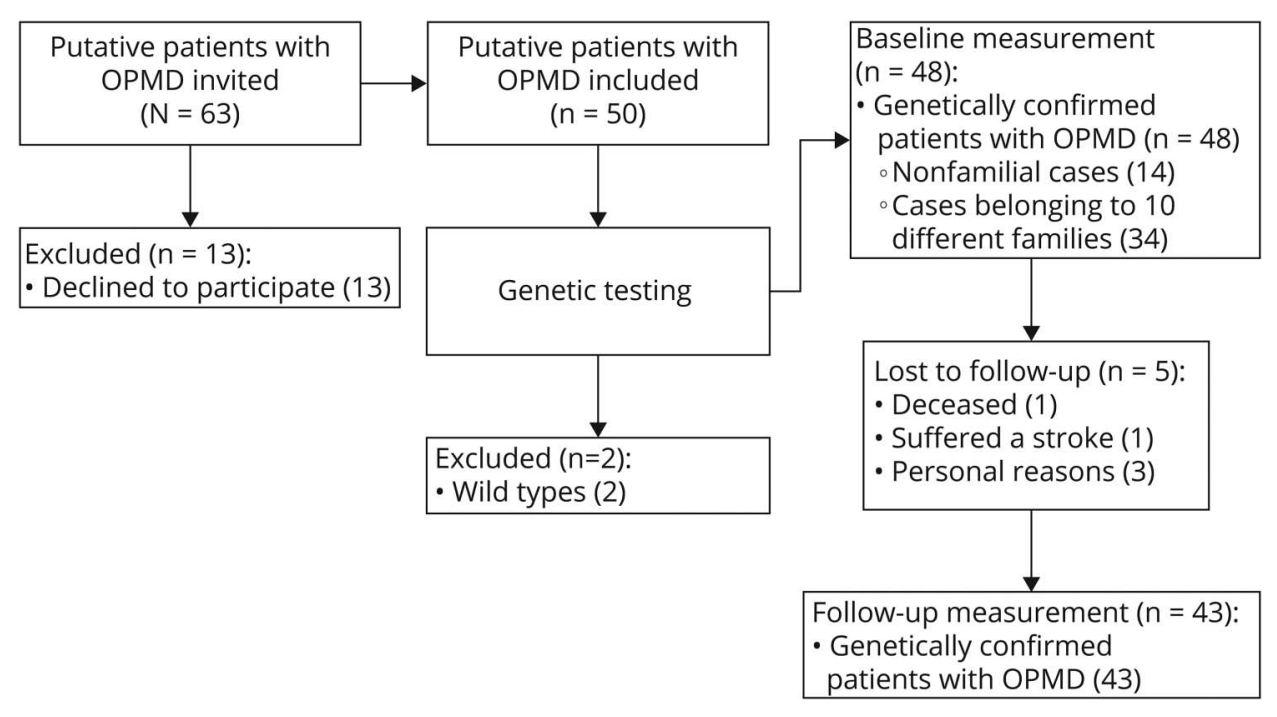

OPMD = oculopharyngeal muscular dystrophy. 
that 2 family members did not have a mutation in the $P A B P N 1$ gene. Therefore, these 2 participants were excluded. The demographic and genetic details of the 43 patients with OPMD are summarized in Table 1. Four patients did not have any complaints at baseline; they are further referred to as asymptomatic carriers. The mean time between the 2 visits was 20 months (median 20 months, range 17-24 months).

At follow-up, 2 of 4 asymptomatic carriers reported subjective complaints and became symptomatic carriers; 1 individual reported "tired legs and difficulty climbing stairs," and the other reported "a hoarse voice and difficulty with simultaneous tasks like eating and walking."

\section{Clinical Measures}

Nine of the 21 measures were not normally distributed, with 3 having a value of $p<0.05$. However, when the Wilcoxon signed-rank test was used instead, the significance of the $p$ values did not change. Table 2 shows the mean percentages of worsening on the 21 measures, of which 10 proved statically significant.

\section{Muscle Strength}

\section{Fixed Dynamometry}

Fixed dynamometry of the deltoid muscle (left side), quadriceps (left side), and iliopsoas muscle (both sides) was

Table 1 Patient Characteristics

\begin{tabular}{ll}
\hline Patient characteristics $(\mathbf{n}=\mathbf{4 3})$ & \\
\hline Mean age at baseline (range), $\mathbf{y}$ & $60.2(44-79)$ \\
\hline Sex, men/women, $\mathbf{n}$ & $21 / 22$ \\
\hline Mean age at onset (range), $\mathbf{y}$ & $50.3(37-73)$ \\
\hline Initial symptom, $\mathbf{n}$ & 18 \\
\hline Ptosis & 17 \\
\hline Dysphagia & 3 \\
\hline Leg weakness & 1 \\
\hline Unknown & 4 \\
\hline None (asymptomatic carrier) & 2 \\
\hline GCN, $\mathbf{n}$ & 3 \\
\hline $\mathbf{1 1 / 1 1 ^ { a }}$ & $\mathbf{2}$ \\
\hline $\mathbf{1 0 / 1 2}$ & 23 \\
\hline $\mathbf{1 0 / 1 3}$ & 3 \\
\hline $\mathbf{1 0 / 1 4}$ & \\
\hline $\mathbf{1 0 / 1 5}$ & \\
\hline $\mathbf{1 0 / 1 6}$ & \\
\hline
\end{tabular}

a No differences in the clinical phenotype and pathologic expression between the recessive and dominant cases were found. Therefore, we did not exclude the recessive (GCN)11/(GCN) 11 cases. ${ }^{46}$ performed in 39 patients. Thirty-eight patients underwent fixed dynamometry of the deltoid muscle and quadriceps (right side). Some patients were not able to perform the tasks due to injuries or technical errors.

All dynamometry measures showed a statistically significant decline over 20 months (Table 2, up to $27 \%$ decline), except for the iliopsoas muscle of the left leg (mean decline $8.7 \%$ [95\% CI $-18.3 \%$ to $0.1 \%]$ ). The deltoid muscle showed the largest strength deterioration over time (Figure 2A, left arm mean decline $24 \%$ [95\% CI $-16.8 \%$ to $-30.2 \%$ ], right arm mean decline $27 \%$ [95\% CI $-16.7 \%$ to $-36.9 \%]$ ).

\section{Maximum Isometric Tongue Strength}

Maximum tongue strength showed a mean decline of $9.9 \%$ over 20 months (95\% CI $-5.6 \%$ to $-14.9 \%$, Table 2 and Figure 2B).

\section{Manual Muscle Testing (MRC Scale)}

The MRC sum score of all muscles showed a mean decline of $2.5 \%$ between baseline and follow-up (Table 2, 95\% CI $-0.9 \%$ to $-4.1 \%)$. The MRC grading also showed a small but significant decrease of 0.1 to 0.2 points at follow-up for 3 individual muscle groups: hip adduction (both sides mean difference 0.19, $p=0.010$ ), elbow flexion (right side mean difference $0.11, p=0.024$, left side mean difference $0.10, p=$ 0.044 ), and shoulder abduction (right side mean difference $0.14, p=0.032$, left side mean difference $0.14, p=0.013$ ).

\section{Functional Capacity}

\section{Stair-Walking Test}

Thirty-four patients showed a mean decline of $12.5 \%$ (Figure 2C, [95\% CI $-19.6 \%$ to $-5.4 \%]$ ). Six patients at baseline and 9 patients at follow-up were not able to perform the stairwalking test due to severe muscle weakness in the legs.

\section{Motor Function Measure}

Part D1 of the MFM test, concerning stance tasks and transfers, showed a mean decline of $7.1 \%$ (95\% CI $-2.4 \%$ to $-11.7 \%$, Table 2 and Figure 2D). Parts D2 and D3 of the MFM did not show a significant change over 20 months $(p>0.05)$.

\section{Swallowing, Chewing, and Speaking}

Swallowing tasks (maximum swallowing speed and maximum swallowing volume) and chewing time did not worsen significantly during follow-up (Table 2). Five patients at baseline and 10 patients at follow-up were not able to perform the TOMASS chewing test. Of the speech capacity tests, only the maximum repetition rate of the syllable /pa/ was significantly slower at follow-up (mean decline 5.3\% [95\% CI $-1.1 \%$ to $-8.8 \%]$ ).

\section{Videofluoroscopy}

Forty-two patients were able to perform the videofluoroscopy. The amount of abnormal pharyngeal residue of thin liquid $(10 \mathrm{~mL})$ in the valleculae increased significantly during follow-up (mean NRRS ratio 0.24 vs $0.13, p=0.007$ ). 
Table 2 Mean (SD) at Baseline and Follow-up and Percentage of Decrease of the Muscle Strength and Functional Capacity Measurements

\begin{tabular}{|c|c|c|c|c|}
\hline & Mean (SD) at baseline & Mean (SD) at follow-up & Percent decrease $(95 \% \mathrm{CI})$ & $p$ Value \\
\hline \multicolumn{5}{|l|}{ Muscle strength } \\
\hline Dynamometry of deltoid right arm, $\mathbf{N}^{\mathrm{a}}$ & $178.7(85.2)$ & $130.8(73.2)$ & $-26.8(-16.7 \text { to }-36.9)^{\mathrm{e}}$ & $<0.001^{\mathrm{e}}$ \\
\hline Dynamometry of deltoid left arm, $\mathbf{N}^{\mathbf{b}}$ & $173.4(84.4)$ & $132.6(65.0)$ & $-23.5(-16.8 \text { to }-30.2)^{\mathrm{e}}$ & $<0.001^{\mathrm{e}}$ \\
\hline Dynamometry of quadriceps left leg, $\mathbf{N}^{\mathbf{b}}$ & $333.6(162.6)$ & $285.8(165.4)$ & $-14.3(-6.0 \text { to }-22.6)^{\mathrm{e}}$ & $0.001^{\mathrm{e}}$ \\
\hline Dynamometry of quadriceps right leg, $\mathrm{N}^{\mathrm{a}}$ & $334.9(167.5)$ & $292.4(170.3)$ & $-12.7(-3.7 \text { to }-21.7)^{\mathrm{e}}$ & $0.007^{\mathrm{e}}$ \\
\hline Dynamometry of iliopsoas right leg, $\mathbf{N}^{\mathrm{b}}$ & $211.6(92.0)$ & $185.7(82.7)$ & $-12.2(-5.5 \text { to }-18.9)^{\mathrm{e}}$ & $0.001^{\mathrm{e}}$ \\
\hline Maximum tongue strength, kPa & $32.2(13.9)$ & $29.0(13.7)$ & $-9.9(-5.6$ to -14.9$)$ & $<0.001^{\mathrm{e}}$ \\
\hline Dynamometry of iliopsoas left leg, $\mathrm{N}^{\mathrm{b}}$ & $208.8(87.7)$ & $190.7(85.3)$ & $-8.7(-18.3$ to 0.1$)$ & NS \\
\hline MRC sum score (0-130) & $122.0(12.9)$ & $119.0(17.5)$ & $-2.5(-0.9 \text { to }-4.1)^{\mathrm{e}}$ & $0.003^{e}$ \\
\hline Maximum bite force, $\mathrm{kg}$ & $15.2(7.2)$ & $14.9(8.0)$ & $-0.3(-10.5$ to 5.3$)$ & NS \\
\hline \multicolumn{5}{|l|}{ Functional capacity } \\
\hline 10-Step stair test, $\mathrm{s}^{\mathrm{c}}$ & $5.6(1.5)$ & $6.3(2.1)$ & $-12.5(-19.6 \text { to }-5.4)^{\mathrm{e}}$ & $0.001^{\mathrm{e}}$ \\
\hline MFM part D1 score, \% & $79.3(28.7)$ & $73.7(31.3)$ & $-7.1(-2.4 \text { to }-11.7)^{\mathrm{e}}$ & $0.004^{\mathrm{e}}$ \\
\hline Maximum phonation time, s & $15.7(8.2)$ & $14.8(7.7)$ & $-5.7(-15.3$ to 3.8$)$ & NS \\
\hline Maximum repetition rate /pa/, syl/s & $5.7(0.6)$ & $5.4(0.8)$ & $-5.3(-1.1 \text { to }-8.8)^{\mathrm{e}}$ & $0.014^{\mathrm{e}}$ \\
\hline Maximum swallowing volume, $\mathrm{mL}$ & $29.6(18.9)$ & $28.1(17.6)$ & $-5.1(-13.9$ to 3.4$)$ & NS \\
\hline Maximum repetition rate /pataka/, syl/s & $4.1(0.6)$ & $4.0(0.6)$ & $-2.4(-4.9$ to 4.9$)$ & NS \\
\hline Maximum swallowing speed, mL/s & $10.0(7.2)$ & $9.6(7.2)$ & $-4.0(-13.0$ to 4.0$)$ & NS \\
\hline MFM part D3 score, \% & $98.1(4.4)$ & $96.9(8.6)$ & $-1.2(-3.3$ to 0.7$)$ & NS \\
\hline MFM part D2 score, \% & $96.8(8.4)$ & $95.8(10.6)$ & $-1.0(-2.6$ to 0.4$)$ & NS \\
\hline Maximum repetition rate /ta/, syl/s & $5.4(0.6)$ & $5.4(0.7)$ & $0(-3.7$ to 1.9$)$ & NS \\
\hline Maximum repetition rate /ka/, syl/s & $5.0(0.8)$ & $5.0(0.6)$ & $0(-4.0$ to 2.0$)$ & NS \\
\hline TOMASS chewing time, $s^{d}$ & $59.4(28.4)$ & $53.9(25.8)$ & $9.3(-2.4$ to 20.9$)$ & NS \\
\hline \multicolumn{5}{|c|}{$\begin{array}{l}\text { Abbreviations: } \mathrm{Cl}=\text { confidence interval; MFM = Motor Function Measure; MRC = Medical Researc } \\
\text { TOMASS = Test of Masticating and Swallowing Solids. } \\
\text { Measurements are arranged in order of the degree of disease progression (percent decline). } \\
{ }^{a} n=38 . \\
{ }^{b} n=39 . \\
{ }^{c} n=34 . \\
{ }^{d} n=33 .\end{array}$} \\
\hline
\end{tabular}

The NRRS ratios for the valleculae and pyriform sinus of the other consistencies did not show a significant difference between baseline and follow-up.

Patients showed no aspiration of thick liquids at baseline, while at follow-up, unsafe swallowing (Penetration Aspiration Scale score $>3$ ) was seen during swallowing $10 \mathrm{~mL}$ in $8 \%$ of the patients $(p=0.119)$ and $20 \mathrm{~mL}$ in $3 \%$ of the patients $(p=$ 0.324 ). When patients swallowed $10 \mathrm{~mL}$ thin liquid, unsafe swallowing was less frequent at follow-up (baseline $21 \%$ of all patients, follow-up $10 \%$ of all patients, $p=0.033$ ). No change in aspiration rate was seen for swallowing $20 \mathrm{~mL}$ of thin liquid and solid food.

\section{Ptosis and Ophthalmoplegia}

Ptosis analyses was done for 40 patients; measurements of 3 patients were missing because of poor video quality. At baseline, 31 patients had ptosis. Ptosis had worsened at follow-up for 3 patients: 1 patient went from no ptosis to mild ptosis, and 2 patients went from mild ptosis to severe ptosis. Seventeen patients underwent ptosis correction of the right or left eye at baseline; at follow-up, this increased to 19 patients.

Ophthalmoplegia analyses were performed in 37 patients; measurements of 6 patients were missing due to poor video quality. On the basis of the examination of 2 independent clinicians, subtle ophthalmoplegia was present in 14 of 37 
A. Left deltoid muscle strength

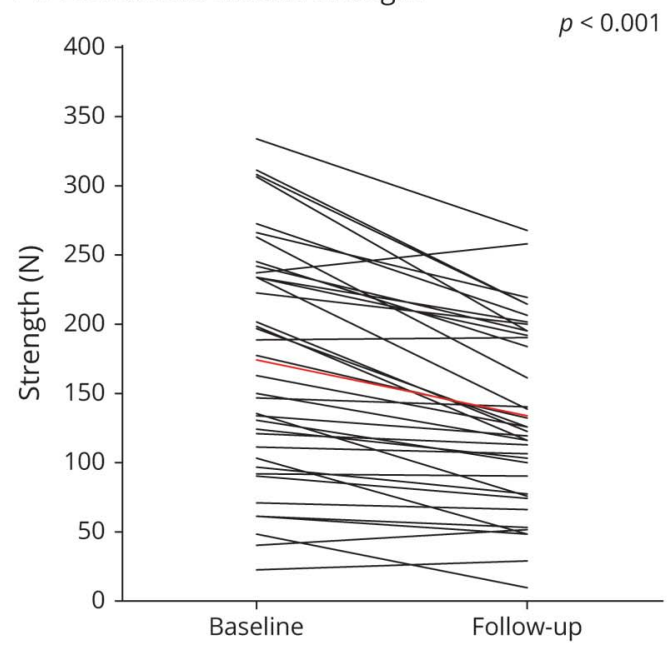

C. 10-step stair test

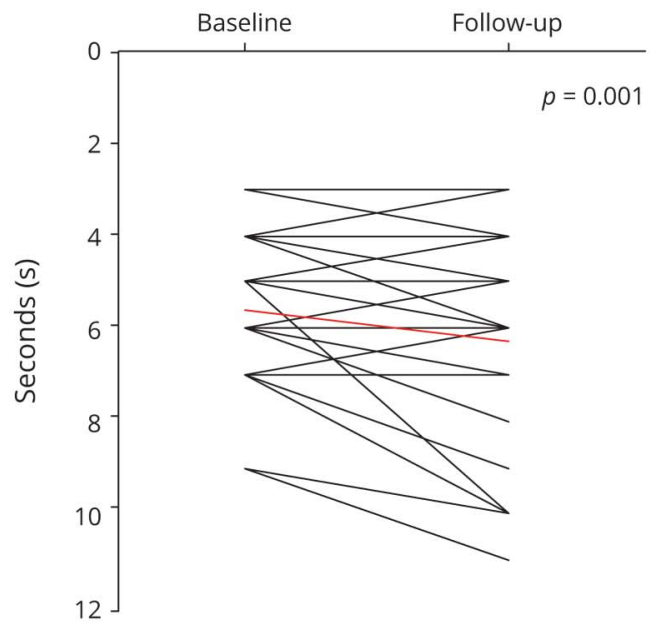

B. Tongue strength

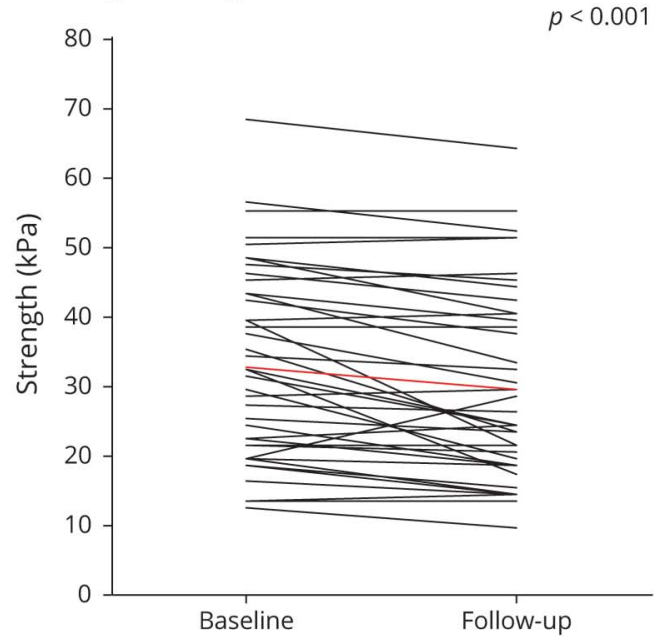

D. MFM D1

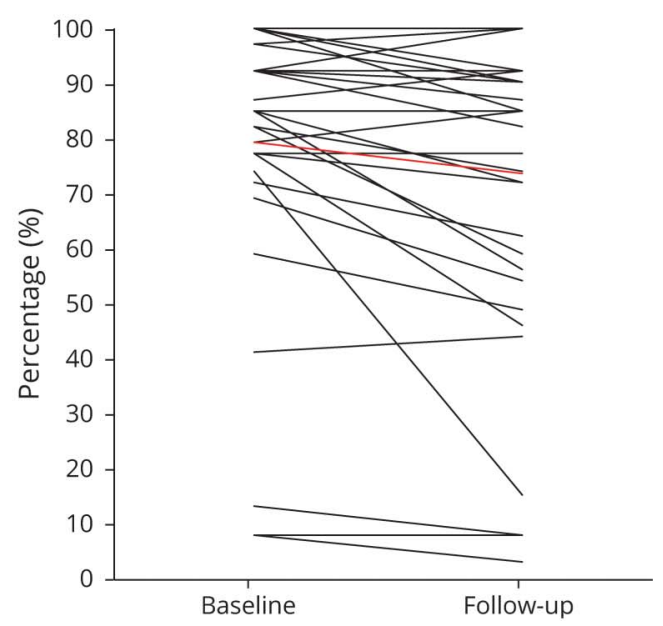

(A) Muscle strength of the left deltoid muscle assessed with dynamometry, (B) tongue strength, (C) 10-step stair test, and (D) part 1 of Motor Function Measure (MFM). Each line represents a patient. Red line shows mean score.

patients at baseline and follow-up, especially in the upper vertical direction.

\section{Quality of Life Scales}

The highest negative impact on quality of life was scored in the INQoL domains of muscle weakness, activities, body image, and fatigue (mean at follow-up 46.8, 37.1, 32.5, 29.6), but none of the domains of the INQoL showed a significant difference between baseline and follow-up. In the SF-36 Health Survey, the physical functioning domain showed a significant deterioration between baseline and follow-up (baseline mean [SD] 61.2 [30.9], follow-up 57.6 [31.4], $p=0.044$ ).

\section{Asymptomatic Carriers}

Each asymptomatic carrier scored somewhat lower on various muscle strength tasks (dynamometry of upper and lower extremities, maximum isometric tongue strength, and maximum bite force) and functional capacity tests (maximum swallowing volume and motor function measure).

\section{Natural History}

The deltoid, quadriceps, and iliopsoas muscles showed the largest disease progression, followed by the tongue muscle (Table 2). Strength decline of these muscles was seen across all patients regardless of the disease severity, that is, in mildly and severely affected patients.

No relationship was found between patient characteristics (disease duration and repeat length $[\mathrm{GCN}]$ ) and disease progression in muscle strength and functional capacity measurements $(p>0.05)$. Fast and slow rates of disease progression were found in asymptomatic and in severely affected patients.

\section{Discussion}

Although disease progression in OPMD is known to be very slow, ${ }^{7}$ the main finding of this nationwide longitudinal cohort 
study is that deterioration can be detected by 8 different clinical measures, regardless of disease severity, during a period of only 20 months. In the absence of comparable studies, this implies that these measures (dynamometry of the deltoid, quadriceps, and iliopsoas muscles; maximum tongue strength; MRC sum score; 10-step stair test; part D1 of the MFM; and maximum speech repetition rate $/ \mathrm{pa} /$ ) could be used to detect disease progression within the time frame of a therapeutic trial.

With dysphagia being the main feature of OPMD, it is highly relevant that tongue strength is one of the features that significantly reduces over an average of 20 months with a mean of $10 \%$. Indeed, the tongue muscle is the most affected oropharyngeal muscle in patients with OPMD as seen in muscle MRI measures. ${ }^{34}$ Moreover, tongue strength is easy to measure with commercially available handheld devices. ${ }^{19}$ However, the strength of the deltoid muscle showed an even greater mean decline over time (27\%). This emphasizes that upper extremity involvement is an important and common feature of OPMD, ${ }^{6}$ and our results show that deltoid strength could be a valuable measure to detect disease progression or therapeutic effect in patients with OPMD.

Disease progression could also be measured by muscle strength measures of the lower extremities. Although some studies reported that the anterior thigh compartment is less affected on muscle MRI measures than the posterior part, ${ }^{10}$ in our dynamometry measurements, there was a significant decline in muscle strength of the quadriceps muscle over 20 months. This may suggest that the strength of the posterior compartment (i.e., hamstrings muscle) might be a sensitive measure of disease progression as well. In our study setup, however, dynamometry of the hamstrings was not possible, so this should be the subject of future studies.

The stair-walking test showed the largest decline of all functional capacity tests. In other natural history studies of slowly progressive neuromuscular disorders, for example, in facioscapulohumeral muscular dystrophy, the stairstep test did not show any clinical progression after 1 year. ${ }^{35}$ Furthermore, the MFM detected disease progression in our cohort, in contrast to an earlier study that showed no progression on the MFM in 8 patients with OPMD over a follow-up period of 8 to 16 months. ${ }^{16}$

Except for reduced tongue strength and maximum repetition rate of $/ \mathrm{pa} /$, no significant decrease was found in the functional capacity tests of chewing, swallowing, and speaking. Even maximum swallowing speed, which at baseline with a mean of $10 \mathrm{~mL} / \mathrm{s}$ was already far below normal $(25 \mathrm{~mL} / \mathrm{s}){ }^{31}$ was only slightly and insignificantly reduced after 20 months. Apparently, it is not sensitive enough to detect a decline within 20 months, or swallowing is already so slow that further deterioration becomes less likely (bottom effect). During videofluoroscopy, only a few changes were seen. Unsafe swallowing occurred less frequently in those ingesting $10 \mathrm{~mL}$ thin liquid at follow-up, which may reflect compensatory actions preventing unsafe swallowing or a learned response between baseline and follow-up measurements. However, a small deterioration in unsafe swallowing was seen after ingestion of thick liquids. Thus, videofluoroscopy does appear to be a less appropriate technique to detect swallowing deterioration in OPMD over 20 months.

Typically, healthy people very slowly deteriorate on musclerelated tasks because of aging (normal age-related changes). Hence, in our previous work, ${ }^{31}$ we compared patients with OPMD with age-matched Dutch healthy controls on swallowing, chewing, and speaking tasks. Patients with OPMD scored significant lower on these tasks compared to agematched healthy controls. In addition, for the stairstep test, healthy controls of approximately the same mean age (58.4 years) as our OPMD group showed much faster stairstep times compared to our OPMD group (mean per step 0.336 seconds vs 0.56 seconds). ${ }^{36}$ OPMD is suggested to be an accelerated aging disorder, ${ }^{37,38}$ so we expect that the disease progression on clinical outcome measures will be greater in patients with OPMD than in age-matched healthy controls. However, to the best of our knowledge, there are no longitudinal studies on the clinical outcome measures in healthy controls. The goal of this study was to detect changes on clinical outcome measures in patients with OPMD, which will be caused by disease progression and aging. A direct comparison to controls would explain this further but was not the scope of the current study.

At follow-up, 2 of the 4 asymptomatic carriers had become symptomatic. On an individual level, each patient scored lower on various measures at follow-up, and that measure corresponded to the subjective complaints of the patient (i.e., difficulty climbing stairs and tired legs). Larger cohorts of asymptomatic OPMD carriers may give more insights into the subtle signs of disease onset but are difficult to perform due to the rarity of the disease and the difficulty in finding asymptomatic carriers.

Future longitudinal studies with larger (international) cohorts can also observe the natural history of patients with OPMD per age group. In this study, analyses by age group were not possible due to the small number of cases per age. In addition, within-family analyses were not feasible in our study. Although 10 different families were identified within our study, 5 of them were very small (only 2 family members). Still, similarities between family members might overestimate the magnitude and precision of the estimated changes over time, suggesting that in future studies this should be taken into account as well. However, because OPMD is a rare disease, it is hard to perform large studies to allow such analyses.

According to the INQoL, the quality of life of our patients with OPMD was reduced by several factors, but mostly by muscle weakness and fatigue, which is in accordance with previous studies on the quality of life in patients with 
OPMD. ${ }^{39,40}$ Similar quality of life scores were also found in other populations with muscular dystrophies. ${ }^{41}$ Quality of life was not further reduced at follow-up except that patients' health status was slightly reduced according to the SF-36 Health Survey, but only in the physical functioning domain. This resonates with our main finding that captured disease progression on 8 of the strength and functional capacity measures. The overall quality of life scale does not seem to be useful in capturing progression within 20 months.

Some of the changes in clinical outcome measures are small and not likely to have functional implications for patients. However, because the measure may be more sensitive than patients' subjective sense of progression, it is relevant for therapy trials to detect small effects. For the MFM, a minimal clinically important difference is defined as $2.5 \%$ to $5 \%$ change. ${ }^{42,43}$ In our study, a change of $7.1 \%$ was seen in patients with OPMD. For the other clinical measures, no studies exist on the minimal clinically important differences. Future longitudinal studies with the focus on the minimal clinical important differences of clinical outcome measures in patients with OPMD are needed to confirm our findings.

No relationship was found between disease progression and disease duration or genotype. On the contrary, fast and slow rates of disease progression were found in both mildly and severely affected patients. There must be epigenetic or environmental factors that influence disease progression that are not known yet. Larger studies with repeated follow-up measures are needed to ascertain a pattern in progression rates.

The results of this study may be influenced by the following shortcomings. The maximum bite force was measured by a validated tool that measures the bite force with the front teeth but not with the molar teeth. Bite force may have been underestimated by this, although it does not change the value of these longitudinal data. Another limitation is that we may have left relevant measurements out of the examination, despite the carefully composed study protocol. Dynamometry measurements to assess the strength of the hamstring muscles may be relevant, but also spirometry to measure vital force capacity is suggested to be relevant in OPMD in relation to dysphagia and dysarthria. ${ }^{31}$ Furthermore, for 2 measures, some patients were unable to perform the task (10 patients for TOMASS chewing time and 9 patients for stair-walking test), which suggests underestimation. This could have implications for the magnitude of the differences. Furthermore, judging ophthalmoplegia on the video recordings was difficult, and progression was not possible to reliably objectify. Finally, a third time point during follow-up was not feasible within our study design but would allow more solid conclusions on the responsiveness of the outcome measures. Further research is needed to make statements on whether the clinical outcome measures can detect disease progression over a shorter or longer time frame of a therapeutic trial.

An unexpected observation was that although most patients showed disease progression in the muscle strength tests, a few patients performed better at follow-up. Some of them reported that they had developed a more active lifestyle by playing sports or having adapted a walking routine during the study period. We did not systematically ask patients about their daily activities and sports, but it would be interesting to examine whether an active lifestyle may affect muscle strength and functional capacity in patients with OPMD as it did in myotonic dystrophy type 1 and facioscapulohumeral muscular dystrophy. ${ }^{44,45}$

This study shows the feasibility of quantifying disease progression in OPMD within 20 months, the time frame of a drug trial. This paves the way for reliable clinical trials in humans. Equally important is that our results show that weakness of the shoulder girdle and lower limb girdle is more sensitive to changes than the oropharyngeal measurements. However, further research is needed to confirm and explain these findings in larger (international) cohorts.

\section{Acknowledgment}

The authors thank Dr. Mariska Janssen for her help in setting up the dynamometry measurements.

\section{Study Funding}

This project is funded by AFM Téléthon (project No. 17110).

\section{Disclosure}

R.H.M.J.M. Kroon, J.G. Kalf, B.J.M. de Swart, B.M. van der Sluijs, J.C. Glennon, V. Raz, B.G.M. van Engelen, and C.G.C. Horlings report no disclosures relevant to the manuscript. Go to Neurology.org/N for full disclosures.

\section{Publication History}

Received by Neurology October 22, 2020. Accepted in final form July 21, 2021.

Appendix Authors

\begin{tabular}{|c|c|c|}
\hline Name & Location & Contribution \\
\hline $\begin{array}{l}\text { Rosemarie } \\
\text { H.M.J.M. } \\
\text { Kroon, MA }\end{array}$ & $\begin{array}{l}\text { Radboud University Medical } \\
\text { Center, the Netherlands }\end{array}$ & $\begin{array}{l}\text { Acquisition and analysis of } \\
\text { data, drafting of the } \\
\text { manuscript and tables/ } \\
\text { figures }\end{array}$ \\
\hline $\begin{array}{l}\text { Johanna G. } \\
\text { Kalf, PhD }\end{array}$ & $\begin{array}{l}\text { Radboud University Medical } \\
\text { Center, the Netherlands }\end{array}$ & $\begin{array}{l}\text { Study concept and design, } \\
\text { acquisition, analysis, } \\
\text { interpretation of data, } \\
\text { revision of the manuscript }\end{array}$ \\
\hline $\begin{array}{l}\text { Bert J.M. de } \\
\text { Swart, PhD }\end{array}$ & $\begin{array}{l}\text { Radboud University Medical } \\
\text { Center, the Netherlands }\end{array}$ & $\begin{array}{l}\text { Study concept and design, } \\
\text { revision of the manuscript }\end{array}$ \\
\hline $\begin{array}{l}\text { Barbara M. } \\
\text { van der } \\
\text { Sluijs, MD, } \\
\text { PhD }\end{array}$ & $\begin{array}{l}\text { Gelre Hospital, the } \\
\text { Netherlands }\end{array}$ & Revision of the manuscript \\
\hline $\begin{array}{l}\text { Jeffrey C. } \\
\text { Glennon, } \\
\text { PhD }\end{array}$ & $\begin{array}{l}\text { University College Dublin, } \\
\text { Ireland }\end{array}$ & Revision of the manuscript \\
\hline $\begin{array}{l}\text { Vered Raz, } \\
\text { PhD }\end{array}$ & $\begin{array}{l}\text { Leiden University Medical } \\
\text { Centre, the Netherlands }\end{array}$ & Revision of the manuscript \\
\hline
\end{tabular}


Appendix (continued)

\begin{tabular}{lll}
\hline Name & Location & Contribution \\
\hline $\begin{array}{l}\text { Baziel G. van } \\
\text { Engelen, MD, } \\
\text { PhD }\end{array}$ & $\begin{array}{l}\text { Radboud University Medical } \\
\text { Center, the Netherlands }\end{array}$ & $\begin{array}{l}\text { Grant writing, study concept } \\
\text { and design, interpretation of } \\
\text { data, revision of the } \\
\text { manuscript }\end{array}$ \\
\hline $\begin{array}{l}\text { Corinne G.C. } \\
\text { Horlings, } \\
\text { MD, PhD }\end{array}$ & $\begin{array}{l}\text { Radboud University Medical } \\
\text { Center, Maastricht }\end{array}$ & $\begin{array}{l}\text { Study concept and design, } \\
\text { analysis and interpretation } \\
\text { of data, revision of the } \\
\text { the Netherlands }\end{array}$ \\
\hline
\end{tabular}

\section{References}

1. Ruegg S, Lehky Hagen M, Hohl U, et al. Oculopharyngeal muscular dystrophy: an under-diagnosed disorder? Swiss Med Wkly. 2005;135(39-40):574-586.

2. Pulkes T, Papsing C, Busabaratana M, Dejthevaporn C, Witoonpanich R. Mutation and haplotype analysis of oculopharyngeal muscular dystrophy in Thai patients. J Clin Neurosci. 2011;18(5):674-677.

3. Chien YY. Oculopharyngeal muscular dystrophy: an under-diagnosed disease in China? Report a China-born Chinese with PABPN1 mutation and epidemiology review of the literature. J Formos Med Assoc. 2012;111(7):397-402.

4. Agarwal PK, Mansfield DC, Mechan D, et al. Delayed diagnosis of oculopharyngeal muscular dystrophy in Scotland. Br J Ophthalmol. 2012;96(2):281-283.

5. Luk HM, Lo IF, Fu KH, et al. Oculopharyngeal muscular dystrophy: underdiagnosed disease in Hong Kong. Hong Kong Med J. 2013;19(6):556-559.

6. Trollet C, Gidaro T, Klein P, Perie S, Butler-Browne G, Lacau St Guily J. Oculopharyngeal muscular dystrophy. 2001 In: Adam MP, Ardinger HH, Pagon RA, et al., eds. GeneReviews. ${ }^{\circledR}$ Seattle, WA: University of Washington, Seattle; 1993-2019.

7. Brais B. Oculopharyngeal muscular dystrophy: a polyalanine myopathy. Curr Neurol Neurosci Rep. 2009;9(1):76-82.

8. Youssof S, Schrader R, Bear D, Morrison L. Hip flexion weakness is associated with impaired mobility in oculopharyngeal muscular dystrophy: a retrospective study with implications for trial design. Neuromuscul Disord. 2015;25(3):238-246.

9. van der Sluijs BM, Raz V, Lammens M, van den Heuvel LP, Voermans NC, van Engelen BG. Intranuclear aggregates precede clinical onset in oculopharyngeal muscular dystrophy. J Neuromuscul Dis. 2016;3(1):101-109.

10. van der Sluijs BM, Lassche S, Knuiman GJ, et al. Involvement of pelvic girdle and proximal leg muscles in early oculopharyngeal muscular dystrophy. Neuromuscul Disord. 2017;27(12):1099-1105.

11. Chartier A, Simonelig M. Animal models in therapeutic drug discovery for oculopharyngeal muscular dystrophy. Drug Discov Today Technol. 2013;10(1):e103-108.

12. Abu-Baker A, Parker A, Ramalingam S, et al. Valproic acid is protective in cellular and worm models of oculopharyngeal muscular dystrophy. Neurology. 2018;91(6): E551-E561

13. Vest KE, Phillips BL, Banerjee A, et al. Novel mouse models of oculopharyngea muscular dystrophy (OPMD) reveal early onset mitochondrial defects and suggest loss of PABPN1 may contribute to pathology. Hum Mol Genet. 2017;26(17): 3235-3252.

14. Doki T, Yamashita S, Wei FY, et al. Mitochondrial localization of PABPN1 in oculopharyngeal muscular dystrophy. Lab Invest. 2019;99(11):1728-1740.

15. Raz V, Butler-Browne G, Engelen BGMv, Brais B. 191st ENMC International Workshop: recent advances in oculopharyngeal muscular dystrophy research: from bench to bedside 8-10 June 2012, Naarden, the Netherlands. Neuromuscul Disord. 2013;23(6):516-523.

16. Fischmann A, Hafner P, Fasler S, et al. Quantitative MRI can detect subclinical disease progression in muscular dystrophy. J Neurol. 2012;259(8):1648-1654.

17. van Engelen BG, van Veenendaal H, van Doorn PA, et al. The Dutch neuromuscular database CRAMP (Computer Registry of All Myopathies and Polyneuropathies): development and preliminary data. Neuromuscul Disord. 2007;17(1):33-37.

18. Council MR. Aids to the Investigation of Peripheral Nerve Injuries. Her Majesty's Stationary Office; 1976.

19. Robin DA, Goel A, Somodi LB, Luschei ES. Tongue strength and endurance: relation to highly skilled movements. J Speech Hear Res. 1992;35(6):1239-1245.
20. Berard C, Payan C, Hodgkinson I, Fermanian J; Group MFM Collaborative Study Group. A motor function measure for neuromuscular diseases: construction and validation study. Neuromuscul Disord. 2005;15(7):463-470.

21. Nightingale EJ, Pourkazemi F, Hiller CE. Systematic review of timed stair tests. J Rehabil Res Dev. 2014;51(3):335-350.

22. Huckabee ML, McIntosh T, Fuller L, et al. The Test of Masticating and Swallowing Solids (TOMASS): reliability, validity and international normative data. Int J Lang Commun Disord. 2018;53(1):144-156.

23. Nathadwarawala KM, Nicklin J, Wiles CM. A timed test of swallowing capacity for neurological patients. J Neurol Neurosurg Psychiatry. 1992;55(9):822-825.

24. Stepman G, Paepens M, DeHeyder E, Beeckman A, Kalf J. Maximum swallowing speed: comparison between Flemish and Dutch normal values. Dysphagia. 2020;35:154-155.

25. Paepens M, Stepman G, DeHeyder E, Beeckman A, Kalf J. Maximum swallowing volume: comparison between Flemish and Dutch normal values. Dysphagia. 2020;35: 155-156.

26. Speyer R, Bogaardt HC, Passos VL, et al. Maximum phonation time: variability and reliability. J Voice. 2010;24(3):281-284.

27. Gadesmann M, Miller N. Reliability of speech diadochokinetic test measurement. Int J Lang Commun Disord. 2008;43(1):41-54.

28. Maslan J, Leng X, Rees C, Blalock D, Butler SG. Maximum phonation time in healthy older adults. J Voice. 2011;25(6):709-713.

29. Goy H, Fernandes DN, Pichora-Fuller MK, van Lieshout P. Normative voice data for younger and older adults. J Voice. 2013;27(5):545-555.

30. Knuijt S, Kalf JG, Engelen BGMv, Swart BJMd, Geurts ACH. The Radboud Dysarthria Assessment: development and clinimetric evaluation. Folia Phoniatr Logop 2017;69(4): 143-153.

31. Kroon R, Horlings CGC, de Swart BJM, van Engelen BGM, Kalf JG. Swallowing, chewing and speaking: frequently impaired in oculopharyngeal muscular dystrophy. J Neuromuscul Dis. 2020;7(4):483-494.

32. Seesing FM, van Vught LE, Rose MR, Drost G, van Engelen BG, van der Wilt GJ. The individualized neuromuscular quality of life questionnaire: cultural translation and psychometric validation for the Dutch population. Muscle Nerve 2015;51(4):496-500.

33. Ware JE Jr., Sherbourne CD. The MOS 36-item Short-Form Health Survey (SF-36), I: conceptual framework and item selection. Med Care. 1992;30(6):473-483.

34. Alonso-Jimenez A, Kroon R, Alejaldre-Monforte A, et al. Muscle MRI in a large cohort of patients with oculopharyngeal muscular dystrophy. J Neurol Neurosurg Psychiatry. 2019;90(5):576-585.

35. Andersen G, Dahlqvist JR, Vissing CR, Heje K, Thomsen C, Vissing J. MRI as outcome measure in facioscapulohumeral muscular dystrophy: 1-year follow-up of 45 patients. J Neurol. 2017;264(3):438-447.

36. Parisi SL, Heroux ME, Culham EG, Norman KE. Functional mobility and postural control in essential tremor. Arch Phys Med Rehabil. 2006;87(10):1357-1364.

37. Anvar SY, Raz Y, Verway N, et al. A decline in PABPN1 induces progressive muscle weakness in oculopharyngeal muscle dystrophy and in muscle aging. Aging. 2013; $5(6): 412-426$.

38. Raz Y, Raz V. Oculopharyngeal muscular dystrophy as a paradigm for muscle aging. Front Aging Neurosci. 2014;6:317.

39. Bachand J, Ladonna K, Venance S, Koopman W. Quality of life in oculopharyngeal muscular dystrophy. Neuromuscul Disord. 2007;17:764-900.

40. Sluijs BMvd, Knoop H, Bleijenberg G, Engelen BGMv, Voermans NC. The Dutch patients' perspective on oculopharyngeal muscular dystrophy: a questionnaire study on fatigue, pain and impairments. Neuromuscul Disord. 2016;26(3):221-226.

41. Jacques MF, Stockley RC, Onambele-Pearson GL, et al. Quality of life in adults with muscular dystrophy. Health Qual Life Outcomes. 2019;17(1):121.

42. Vuillerot C, Payan C, Girardot F, et al. Responsiveness of the motor function measure in neuromuscular diseases. Arch Phys Med Rehabil. 2012;93(12):2251-2256 e2251.

43. Le Goff L, Meilleur KG, Norato G, et al. Responsiveness and minimal clinically important difference of the motor function measure in collagen VI-related dystrophies and laminin alpha2-related muscular dystrophy. Arch Phys Med Rehabil. 2021;102(4):604-610.

44. Okkersen K, Jimenez-Moreno C, Wenninger S, et al. Cognitive behavioural therapy with optional graded exercise therapy in patients with severe fatigue with myotonic dystrophy type 1: a multicentre, single-blind, randomised trial. Lancet Neurol. 2018; 17(8):671-680.

45. Voet NBM, Kooi ELvd, Riphagen II, Lindeman E, Engelen BGMv, Geurts ACH. Strength training and aerobic exercise training for muscle disease. Cochrane Database Syst Rev. 2013;7(7):CD003907.

46. Richard P, Trollet C, Gidaro T, et al. PABPN1 (GCN)11 as a dominant allele in oculopharyngeal muscular dystrophy: consequences in clinical diagnosis and genetic counselling. J Neuromuscul Dis. 2015;2(2):175-180. 


\section{Neurology}

\section{Longitudinal Assessment of Strength, Functional Capacity, Oropharyngeal Function, and Quality of Life in Oculopharyngeal Muscular Dystrophy}

Rosemarie H.M.J.M. Kroon, Johanna G. Kalf, Bert J.M. de Swart, et al. Neurology 2021;97;e1475-e1483 Published Online before print August 11, 2021

DOI 10.1212/WNL.0000000000012640

\section{This information is current as of August 11, 2021}

Updated Information \& Services

References

Subspecialty Collections

Permissions \& Licensing

Reprints including high resolution figures, can be found at: http://n.neurology.org/content/97/15/e1475.full

This article cites 44 articles, 3 of which you can access for free at: http://n.neurology.org/content/97/15/e1475.full\#ref-list-1

This article, along with others on similar topics, appears in the following collection(s):

Muscle disease

http://n.neurology.org/cgi/collection/muscle_disease

Natural history studies (prognosis)

http://n.neurology.org/cgi/collection/natural_history_studies_prognosis

Information about reproducing this article in parts (figures,tables) or in its entirety can be found online at:

http://www.neurology.org/about/about_the_journal\#permissions

Information about ordering reprints can be found online:

http://n.neurology.org/subscribers/advertise

Neurology ${ }^{\circledR}$ is the official journal of the American Academy of Neurology. Published continuously since 1951, it is now a weekly with 48 issues per year. Copyright Copyright ( 2021 The Author(s). Published by Wolters Kluwer Health, Inc. on behalf of the American Academy of Neurology.. All rights reserved. Print ISSN: 0028-3878. Online ISSN: 1526-632X.

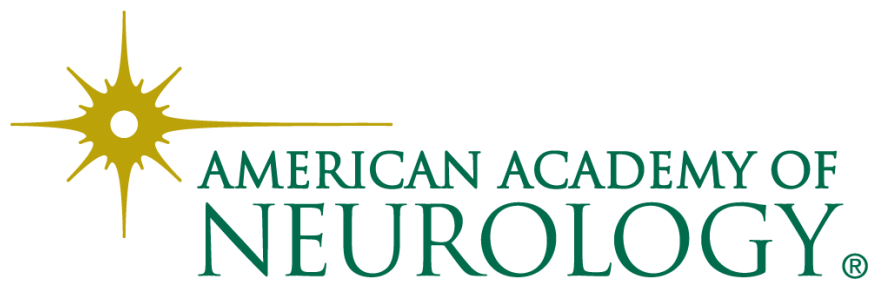

